\title{
Correction to: A Cost Analysis of School-Based Lifestyle Interventions
}

\author{
Marije Oosterhoff ${ }^{1} \cdot$ Hans Bosma ${ }^{2} \cdot$ Onno C. P. van Schayck ${ }^{3} \cdot$ Manuela A. Joore $^{1}$
}

Published online: 29 June 2019

(C) Society for Prevention Research 2019

\section{Correction to: Prevention Science (2018) 19:716-727 https://doi.org/10.1007/s11121-018-0918-1}

In the article, 'A Cost Analysis of School-Based Lifestyle Interventions', we calculated the societal costs of two school-based lifestyle interventions: 'the Healthy Primary School of the Future' and 'the Physical Activity School'. Unfortunately, it became clear to us that the cost calculation for the Physical Activity Schools was not entirely correct.

It was stated that the length of the school day was extended at Healthy Primary Schools of the Future and at Physical Activity Schools to facilitate the implementation of activities. The length of the school day was valued in the cost calculations as it might result in increased productivity of primary caregivers (e.g. more possibilities for work). However, at Physical Activity Schools the length school day did not became longer in comparison to control schools.

The online version of the original article can be found at https://doi.org/ 10.1007/s11121-018-0918-1

Marije Oosterhoff

marije.oosterhoff@mumc.nl

1 Department of Clinical Epidemiology and Medical Technology Assessment (KEMTA), Maastricht University Medical Centre MUMC+/Care and Public Health Research Institute (CAPHRI), Maastricht University, Maastricht, The Netherlands

2 Department of Social Medicine, Care and Public Health Research Institute (CAPHRI), Faculty of Health, Medicine and Life Sciences, Maastricht University, P.O. Box 5800, 6202,

AZ Maastricht, The Netherlands

3 Department of Family Medicine, Care and Public Health Research Institute (CAPHRI), Faculty of Health, Medicine and Life Sciences, Maastricht University, Maastricht, The Netherlands
As a sensitivity analysis we excluded the value of the extended school day. This was done as the value of this cost item is highly uncertain (e.g. gains in productivity of primary caregivers could be offset by potential utility losses). The results of this sensitivity analysis are therefore now representative of the updated base-case results for the Physical Activity Schools. Table 2 represents the costs of HPSF and PAS for the first year of implementation. When excluding the value of the extended school day for PAS, the costs amounted to $€ 505$ per child per year or $€ 3.16$ per child per day. In the hypothetical steady state, the costs were $€ 346$ per child per year or $€ 2.16$ per child per day (Table 3 ).

In the article, we concluded that the costs for the education sector were fully compensated for the Physical Activity School and almost fully compensated for the Healthy Primary School of the Future by the savings within the household sector. Based on the updated calculations, we conclude that a small investment is required for the delivery of the Physical Activity School ( $€ 2.16$ per child per day for the Physical Activity School and $€ 0.96$ for the Healthy Primary School of the Future).

[1] Oosterhoff, M., Bosma, H., van Schayck, O.C.P., Joore, M.A. (2018). A cost analysis of school-based lifestyle interventions. Prevention Science, 19, 716-727.

Publisher's Note Springer Nature remains neutral with regard to jurisdictional claims in published maps and institutional affiliations. 


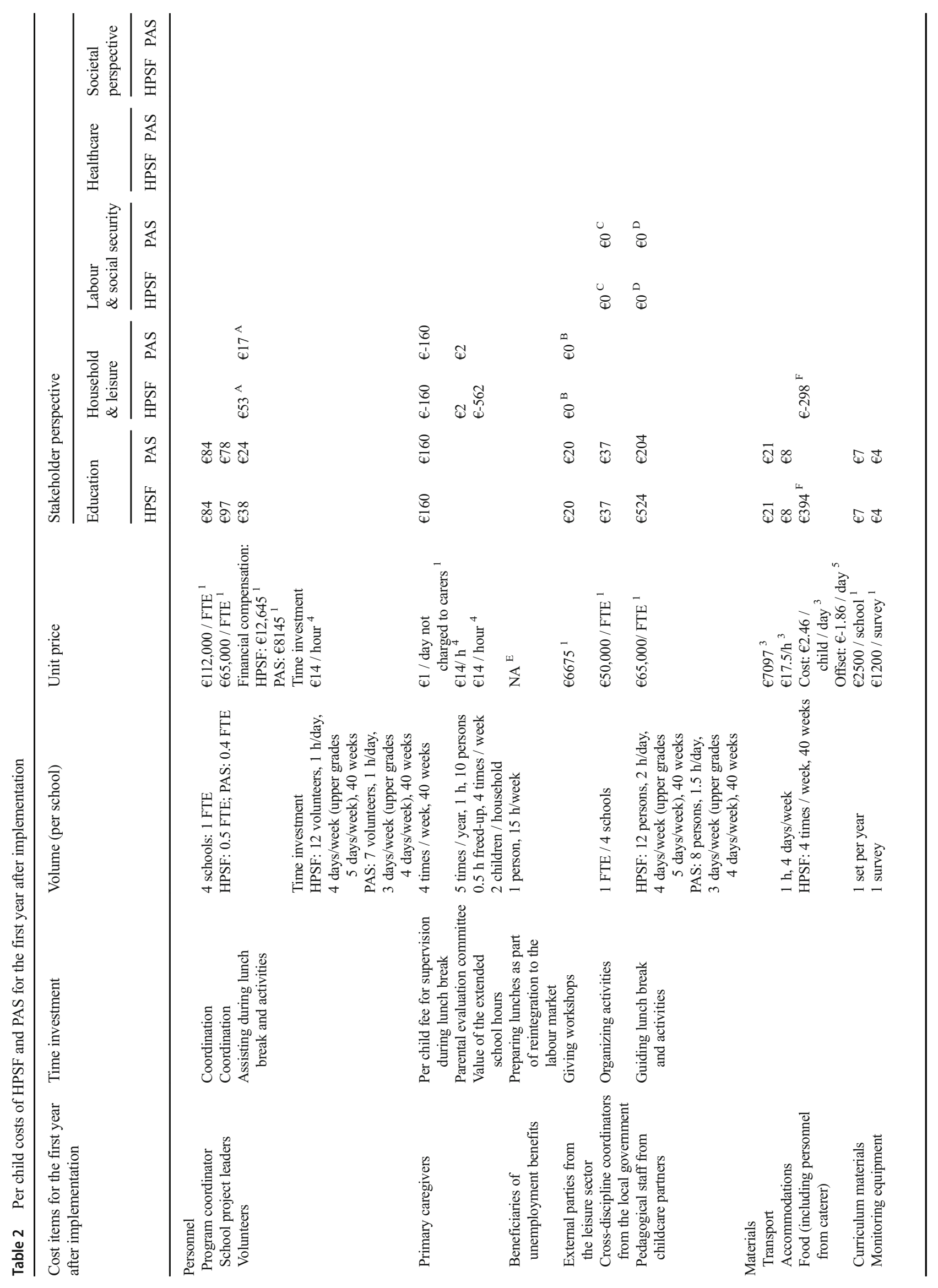




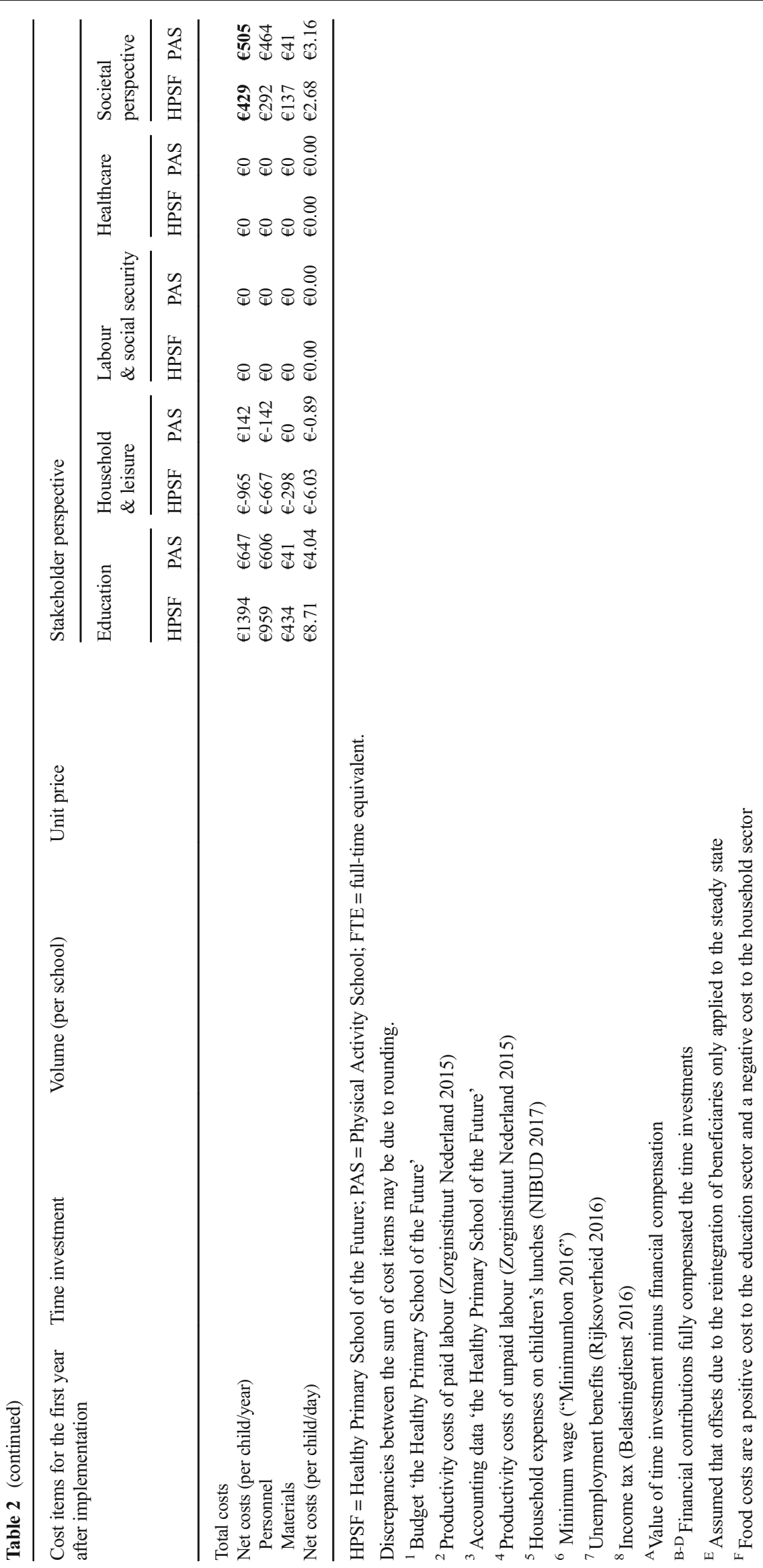




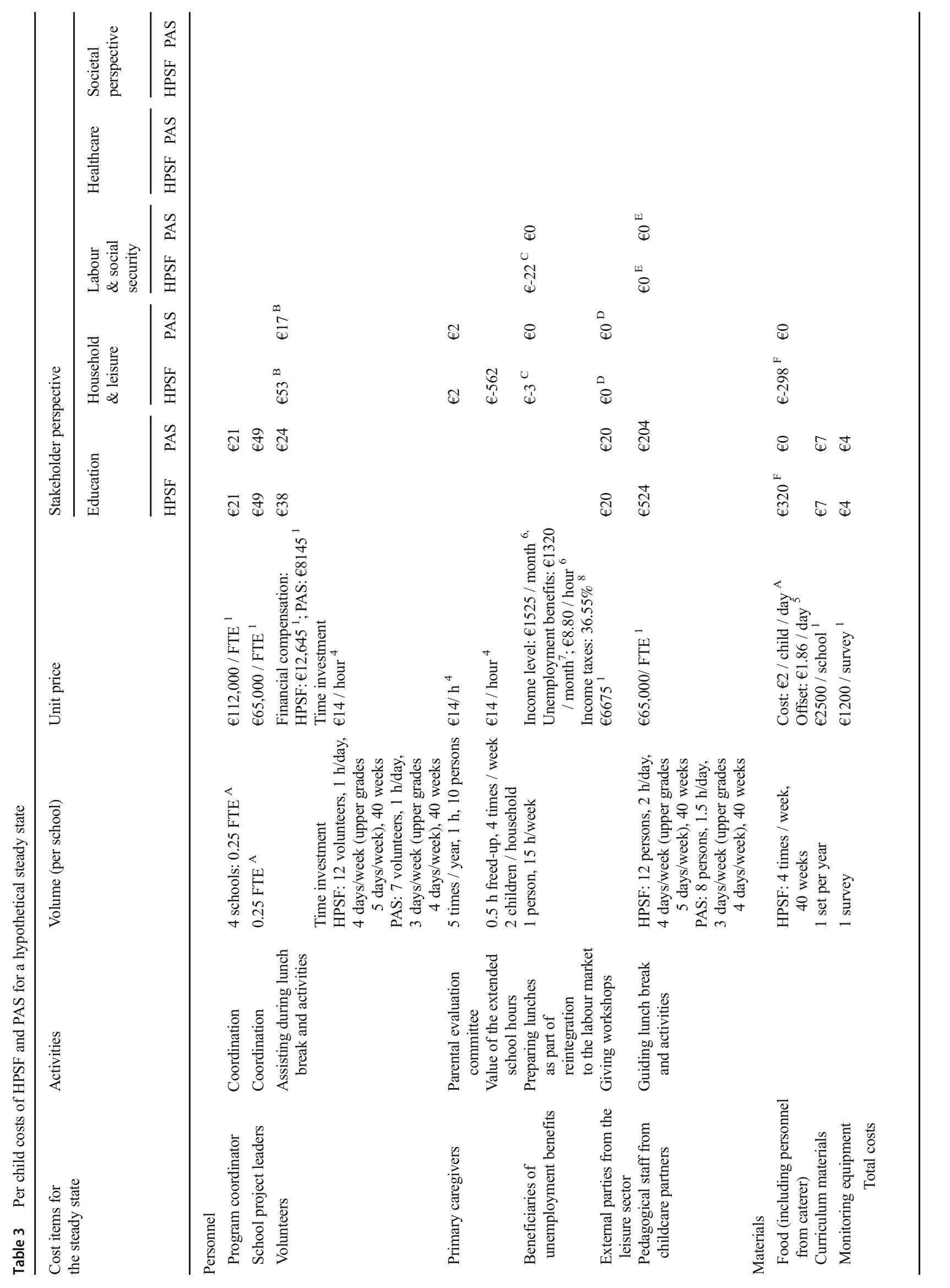




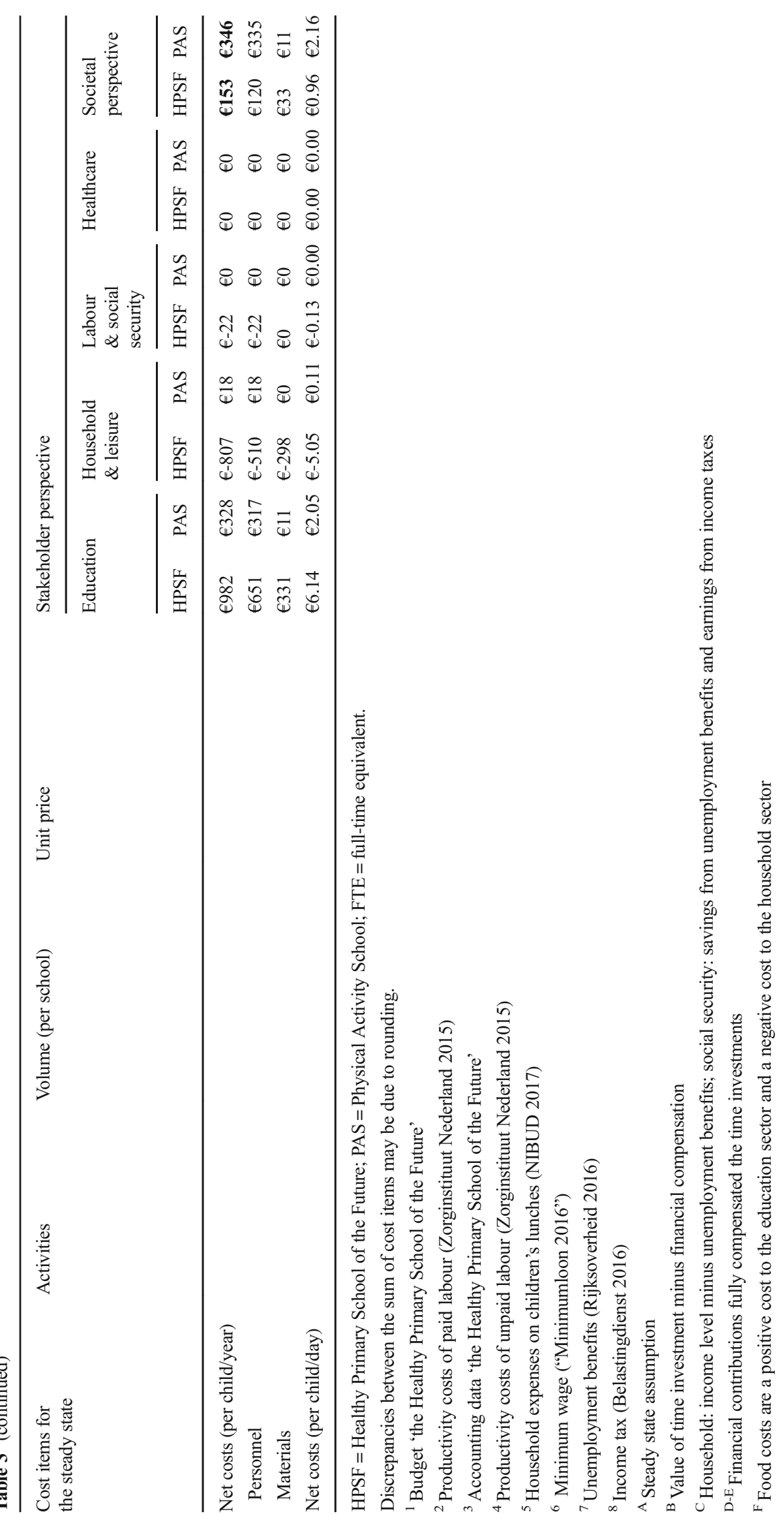

